\title{
Computer aided exercise electrocardiographic testing and coronary arteriography in patients with angina pectoris and with myocardial infarction
}

\author{
JAN-ERIK ANGELHED, * THORVALD I BJURŐ,† JAN EJDEBACK, $¥$ KJELL SELIN, \\ DAVID SCHLOSSMAN, $\$$ LAWRENCE S C GRIFFITH, „| ROBERT BERGSTRAND,

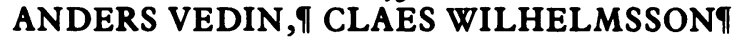

From the Department of Clinical Physiology, Sahlgren Hospital, Gothenburg, Sweden

SUMMARY A set of electrocardiographic criteria for the diagnosis of coronary artery disease was evaluated in two different groups of patients examined by computer aided 12 lead exercise electrocardiographic stress testing and coronary arteriography. One group consisted of patients with severe angina pectoris and the other of patients who had suffered a myocardial infarction three years before the study. Angiographically determined categories of patients could be identified with satisfactory precision by the electrocardiographic criteria under test in the patients with angina pectoris but not in those with infarction. A new method of classifying patients on the basis of data from coronary arteriography improved the correlation with ST segment analysis compared with conventional classification.

Exercise electrocardiographic testing is commonly used to detect coronary artery disease and also to evaluate the severity of disease and to observe the effect of treatment. ${ }^{1}$ Several reports suggest that the electrocardiographic response during exercise may correlate with the findings of coronary arteriography. ${ }^{2-4}$ Results have, however, also shown that exercise electrocardiographic testing poorly identifies patients with coronary artery disease. ${ }^{5-7}$

Several factors influence the results of such investigations: (a) patient selection; $(b)$ the reference method; $(c)$ the definition of disease by the reference method; and $(d)$ the procedures used in applying a method.

The aim of this investigation was to determine whether a set of ST segment amplitude criteria could identify critical coronary lesions in two differently

Requests for reprints to Dr Jan-Erik Angelhed, Department of Applied Electronics, Chalmers University of Technology, S-412 96 Göteborg, Sweden.

Present addresses: *Department of Applied Electronics, Chalmers University of Technolozy; S-412 96 Göteborg, Sweden; +Department of Clinical Physiology, ¥Department of Cardiology, SDepartment of Rediology I, Sahleren Hoopital, S-413 45 Götebors, Sweden; |Department of Medicine, The Johns Hopkins Hoopital and School of Medicine, Baltimore, Maryland, USA; and IDepartment of Medicine, Ottra Hoepital, S-416 85 Göteborg, Sweden.

Accepted for publication 6 March 1984 selected groups of patients, one group consisting of patients with severe angina pectoris, who were to undergo coronary bypass surgery, and the other of patients who had had a myocardial infarction. A further aim was to determine whether the correlation between the results of exercise testing and coronary arteriography was improved by applying a new method of classifying patients angiographically.

\section{Patients and methods}

Two groups of patients with documented coronary artery disease were studied. The method of selection for the two groups was quite different.

\section{PATIENT SELECTION}

Angina group-This consisted of 63 men and four women (age range 34-63 (mean 55). years) with severe angina pectoris (NYHA functional classes III and IV) being assessed for possible coronary bypass surgery. Beta blocking agents were given to $87 \%$ of the patients, and the dose was not reduced before the exercise test.

Infarction group-This consisted of 42 men (age range 31-59 (mean 50) years) who had survived a clinically documented myocardial infarction three years earlier. Coronary arteriography had been per- 
formed three months after the infarction. As part of a follow up study these patients were re-examined regardless of the presence of symptoms. Beta blocking agents were given to all of these patients. The night before exercise testing, however, only half the dose was taken, and no beta blocker was taken on the morning of the test.

Twelve patients (18\%) from the angina group were excluded from the ST segment analysis because they showed abnormal $Q$ waves (Minnesota Codes 1.1 and 1.2 ) in the chest to head lead $\mathrm{CH} 2$, and 11 patients (26\%) were excluded from the infarction group for the same reason.

Angina subgroup-Sixty per cent of the patients with angina had had a myocardial infarction between 20 years and three months before examination. To assess the influence of an infarction in these patients the group was subdivided into those with $(a)$ a definite infarction $(n=29),(b)$ an uncertain infarction $(n=11)$, and $(c)$ absence of infarction $(n=27)$. A patient was classified as having a definite infarction or an uncertain infarction according to the diagnosis at the time of the infarction.

\section{EXERCISE TESTING}

The patients were examined by exercise testing on the day before coronary arteriography. The work was performed on a bicycle ergometer. A minicomputer was used to process and store the electrocardiographic signals recorded by an electrocardiograph. The lead system consisted of six chest to head leads (CH1CH6) and a modification of the standard six limb leads. ${ }^{8}$ It was possible to obtain all the information from the six limb leads by recording only two signals. The six chest to head leads and limb leads I and II were digitised at a rate of $500 \mathrm{~Hz}$ continuously throughout the test, and an eight channel average complex was calculated and stored on disk every 10 seconds. ?

The starting workload was $30 \mathrm{~W}$ and was increased by $10 \mathrm{~W}$ per minute until intolerable chest pain, intense fatigue, a decrease in blood pressure, or significant arrhythmia occurred. The electrocardiogram was then recorded during a 10 minute period of rest after exercise.

\section{ECG measurements}

The ST segment displacement amplitudes were measured $60 \mathrm{~ms}$ after the end of QRS complex with the PQ level as a reference level. The ST60 depression was calculated as the change in ST amplitude from a value recorded while the patient was resting on the bicycle before exercise to that recorded at maximal workload.

ST segment displacement was also determined in relation to heart rate. To make the measurement of
ST segment displacement less sensitive to the influence of the $T$ wave at high heart rates, the time offset from the end of QRS complex to the point of amplitude measurement was decreased. At heart rates above 120 beats/min a factor of the square of (120/ heart rate) was used to adjust the offset. This correction factor reflects the change of position of the $T$ wave with varying heart rate. ${ }^{10}$

The criteria for ST segment displacement were: $(a)$ ST60 depression $\geqslant 0.033 \mathrm{mV}$ in lead $I,(b)$ ST60 depression $\geqslant 0.2 \mathrm{mV}$ in any chest lead, and $(c)$ either of the two above or both. ${ }^{11}$

\section{CORONARY ARTERIOGRAPHIC CLASSIFICATION}

Coronary arteriography was performed using Judkins's technique. 12 The findings for the angina group were coded according to the American Heart Association grading system. ${ }^{13}$ In the infarction group the findings were coded according to Friesinger et al. ${ }^{14}$ The data for these two groups were collected as part of a separate study by experienced examiners. In addition, the clinical report of the arteriographic results was available.

\section{Vessel disease}

In the present study the term "significant narrowing" denoted a diameter reduction of $>50 \%$. "Critical coronary disease" denoted the presence of significant narrowing at one or more sites in the main left coronary artery (MLCA) or in the left anterior descending artery proximal to the first septal branch or in all three major branches simultaneously. ${ }^{11}$

\section{Global flow index}

An index was designed to estimate the effect of narrowing on the ratio of actual to normal blood flow at high workloads. At each site the value of the index is determined by the proximal narrowing and collaterals. As detailed data are missing on how these and other factors affect the arterial flow, simple relations were used to calculate the index. A narrowing was represented by the diameter rather than by the area, mainly for the sake of simplicity. In the aortic root, where the coronary arteries originate, the flow index is set equal to 1 . The effect of a diameter narrowing of $x$ per cent is given by: index (distal)=index (proximal) $(100-x) / 100$. The index is constant between adjacent narrowings. A vessel segment supported by collaterals can have a higher index value distal to a narrowing than proximal to it. A collateral described as having a good flow is set to contribute to the index at the collateral destination by: (index (collateral source)-index (collateral destination))/3. A collateral with a reduced flow will give rise to a proportionally reduced contribution to the index. Blood flow indices calculated at 16 sites in the arterial tree are multiplied by the esti- 
Table 1 Angiographic findings in patients with angina and with myocardial infarction

\begin{tabular}{|c|c|c|c|c|}
\hline & \multicolumn{2}{|c|}{ Angina group } & \multicolumn{2}{|c|}{ Infarction group } \\
\hline & Total No & No studied $\star$ & Total No & No studied* \\
\hline $\begin{array}{l}\text { Total No of patients } \\
\text { No with: }\end{array}$ & 67 & 55 & 42 & 31 \\
\hline $\begin{array}{l}\text { Significant narrowing in MLCA or proximal LAD } \\
\text { Significant } 3 \text { vessel disease } \\
\text { Critical coronary disease } \\
\text { No significant narrowing }\end{array}$ & $\begin{array}{r}41 \\
25 \\
45 \\
4\end{array}$ & $\begin{array}{r}34 \\
20 \\
36 \\
4\end{array}$ & $\begin{array}{r}17 \\
12 \\
22 \\
1\end{array}$ & $\begin{array}{r}12 \\
8 \\
14 \\
1\end{array}$ \\
\hline
\end{tabular}

*After exclusion of patients with abnormal Q waves. MLCA, main left coronary artery; LAD, left anterior descending (artery).

mated corresponding proportions of supported muscle mass. ${ }^{15}$ These modified indices are summed to give a global flow index. A patient's global flow index is used as an estimation of the ratio between the patient's actual and normal supply of blood to the left ventricle during exercise. The range of the global flow index is from 0 , which indicates the existence of several severe proximal narrowings, to 1 , which indicates the absence of narrowing.

An angiographic classification was obtained by assigning patients with a global flow index $\leqslant 0.4$ to a category of severe disease, and patients with a global flow index between 0.4 and 1 to one of less severe disease. The value 0.4 was chosen to obtain groups of approximately the same size as those obtained when classified according to the presence of critical coronary disease.

\section{DATA ANALYSIS}

Significance tests were performed using Student's test.

Sensitivity is defined as the number of true positives divided by the sum of true positives and false negatives. Specificity is defined as true negatives divided by the sum of true negatives and false positives. The predictive value gives the percentage of all positive diagnoses that are correct-that is, true positives divided by the sum of true and false positi res.

\section{Results}

\section{ANGIOGRAPHIC CLASSIFICATION}

The results of coronary arteriography are given in

Table 2 Number of patients in each angiographic category and in both categories combined for the two groups of patients

\begin{tabular}{lll}
\hline Angiographic category & Angina group & Infarction group \\
\hline Critical coronary disease & 36 & 14 \\
Global flow index <0.4 & 41 & 15 \\
Critical coronary disease & & \\
and global flow index & 35 & 9 \\
$<0.4$ & 55 & 31 \\
Total & 5 & \\
\hline
\end{tabular}

Table 1. Most patients in the angina group had significant narrowing, and more patients had critical coronary disease than in the infarction group.

Table 2 shows the distribution of patients according to angiographic classification for the two groups. In the angina group 35 of the 36 patients with critical coronary disease also had a global flow index $<0.4$. The corresponding numbers in the infarction group were nine of 14. Although the number of patients in the infarction group, classified as having severe disease by each of the two methods, was similar, in only $60 \%$ did the classifications overlap.

In the infarction group, 12 patients experienced anginal pain during exercise. Six of these interrupted the exercise test because of chest pain. No correlation was found between the development of angina during exercise and the degree of angiographically determined coronary artery disease (Table 3 ).

Table 4 shows the mean values for maximal workload and heart rate at maximal workload as well as the global flow index. The angina group had values for these indices well below the corresponding values in the infarction group. The differences in mean values for heart rate at maximal load and maximal load between the angina group as a whole and the infarction group as a whole were significant at the $0.1 \%$ level, and for the global flow index the difference was significant at the $2 \%$ level. Within the angina group no significant differences existed in heart rate at maximal workload or in maximal workload between the two angiographic categories.

Table 3 Number of patients in the infarction group presenting with angina pectoris in relation to the angiographic classification

\begin{tabular}{llll}
\hline Angiographic category & \multicolumn{3}{l}{ Angina intensity } \\
\cline { 2 - 4 } & 0 & 1 & 2 \\
\hline No critical coronary disease & 10 & 2 & 5 \\
Critical coronary disease & 9 & 4 & 1 \\
Global flow index $>0.4$ & 10 & 3 & 3 \\
Global flow index $<0.4$ & 9 & 3 & 3
\end{tabular}

Angina intensity: 0 , no angina; 1 , angina present but not limiting; 2 , angina pectoris was the determining factor for discontinuin the exercise test. 
Table 4 Heart rate at maximum workload, maximum workload, and the global flow index for the two patient groups in relation to the two angiographic classifications

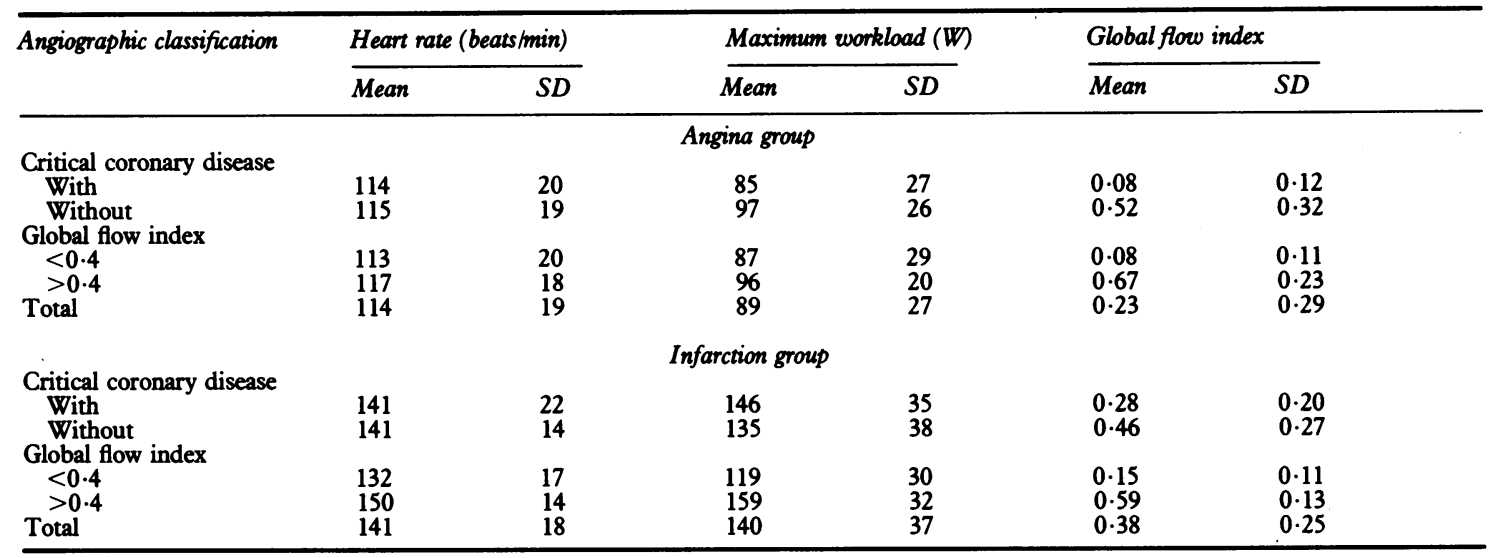

In the infarction group patients with critical coronary disease had the same mean heart rate at maximal workload as those without. The mean maximal load was not significantly higher for patients with critical coronary disease than for those without. When the angiographic classification was based on the global flow index, however, significant differences were noted. Patients with a global flow index of $>0.4$ reached higher heart rates at maximal workload $(p<0.01)$ and higher values for the maximal load $(p<0.002)$ than patients with a value below this limit.

\section{ELECTROCARDIOGRAPHIC CRITERIA}

The evaluation of ST segment changes in terms of sensitivity, specificity, and predictive value for detecting critical coronary disease is shown in Table 5. For all three combinations of leads the sensitivity was significantly lower and the specificity higher in the infarction group than in the angina group.

The use of ST measurements dependent on heart rate resulted in marginal changes for the angina group; this was to be expected since most of these patients had a low maximum heart rate. No increase in the sensitivity for the infarction group was found, although these patients had a mean maximum heart rate of 141 beats/min.

Table 6 shows the relation between electrocardiographic results and the global flow index. As in Table 5 the sensitivity was significantly lower and the specificity higher in the infarction group than in the angina group. When Table 5 and Table 6 are compared the predictive value is higher for all lead combinations in both patient groups. In the angina group there is a consistent lowering of the sensitivity (maximum 5\%) and an increase in the specificity (maximum $11 \%$ ) in all lead combinations when the angiographic classification is based on the global flow index. The corresponding change in the infarction group is an increase in both sensitivity (maximum 18\%) and specificity (maximum $18 \%$ ).

The effect of a previous infarction on the electrocardiographic criteria in the angina group is shown in Table 7 (patients with a $Q$ wave in $\mathrm{CH} 2$ are included). The tendency for an infarction to increase specificity and decrease sensitivity is shown for all three criteria, although the differences are small within the angina group.

Table 5 Sensitivity, specificity, and predictive value (\%) of electrocardiographic ST segment changes for detecting patients with angiographically determined critical coronary disease

\begin{tabular}{|c|c|c|c|c|c|c|}
\hline \multirow[t]{2}{*}{$S T$ segment response } & \multicolumn{3}{|c|}{ Angina group } & \multicolumn{3}{|c|}{ Infarction group } \\
\hline & Sensitivity & Specificity & Predictive value & Sensitivity & Specificity & Predictive value \\
\hline \multirow{2}{*}{$\begin{array}{l}\text { ST segment depression: } \\
\geqslant 0.033 \mathrm{mV} \text { (lead I) } \\
\geqslant 0.2 \mathrm{mV} \text { (any CH lead) } \\
\geqslant 0.033 \mathrm{mV} \text { (lead I) or } \\
\geqslant 0.2 \mathrm{mV} \text { (any CH lead) }\end{array}$} & $\begin{array}{l}92 \\
81\end{array}$ & $\begin{array}{l}68 \\
68\end{array}$ & $\begin{array}{l}85 \\
83\end{array}$ & $\begin{array}{l}29 \\
50\end{array}$ & $\begin{array}{l}76 \\
76\end{array}$ & $\begin{array}{l}50 \\
64\end{array}$ \\
\hline & 94 & 58 & 81 & 50 & 65 & 54 \\
\hline
\end{tabular}


Table 6 Sensitivity, specificity, and predictive value (\%) of ST segment changes for detecting patients with a global flow index $\leqslant 0.4$

\begin{tabular}{|c|c|c|c|c|c|c|}
\hline \multirow[t]{2}{*}{$S T$ segment response } & \multicolumn{3}{|c|}{ Angina group } & \multicolumn{3}{|c|}{ Infarction group } \\
\hline & Sensitivity & Specificity & Predictive value & Sensitivity & Specificity & Predictive value \\
\hline \multirow{2}{*}{$\begin{array}{l}\text { ST segment depression: } \\
\geqslant 0.033 \mathrm{mV} \text { (lead I) } \\
\geqslant 0.2 \mathrm{mV} \text { (any CH lead) } \\
\geqslant 0.033 \mathrm{mV} \text { (lead I) or } \\
\geqslant 0.2 \mathrm{mV} \text { (any CH lead) }\end{array}$} & $\begin{array}{l}88 \\
76\end{array}$ & $\begin{array}{l}79 \\
71\end{array}$ & $\begin{array}{l}92 \\
89\end{array}$ & $\begin{array}{l}47 \\
53\end{array}$ & $\begin{array}{l}94 \\
81\end{array}$ & $\begin{array}{l}88 \\
73\end{array}$ \\
\hline & 90 & 64 & 88 & 60 & 75 & 69 \\
\hline
\end{tabular}

\section{Discussion}

Patients with a $\mathrm{Q}$ wave in lead $\mathrm{CH} 2$ of the resting electrocardiogram were excluded because those with this sign of transmural anterior myocardial infarction show mainly ST segment elevation during exercise. ${ }^{16} 17$

One group consisted solely of men and the other contained $6 \%$ of women. Analysis of the ST segment response in women during stress testing is reported to be difficult, but this cannot explain the present result since the women were in the group in which the ST segment criteria correlated well with the arteriographic findings. Another difference between the groups is the mean age. It is unlikely, however, that the same degree of ischaemia would produce a different ST segment response in relation to age.

The difference between the two groups in the degree of beta blockade at the time of the exercise test should be small, although the infarction group were given a reduced dose 18 hours before the examination. ${ }^{18}$

The formulas for calculating the flow index were chosen because of their simplicity and need modification to reflect the arterial flow more accurately. The length and structure of the narrowing probably also influence the effect of a stenosis on the peak flow. Another important determinant of flow is the myocardial peripheral resistance, which is not easily assessed by coronary arteriography. Vasospasm is a possible obstacle to flow, which may develop during exercise and not at rest during coronary arteriography. Normalisation of the flow index taking into account the presence of infarcted muscle and the accompanying lesser demand for blood supply is suggested as a step towards formulating an index that correlates with ischaemia. A fundamental characteristic of the indices used is that they allow continuous grading of the measurements as opposed to the usual division into groups-for example, critical and noncritical coronary disease. Thus an individual with a $40 \%$ stenosis in the main left coronary artery would be classified as having non-critical disease, whereas with the flow index the stenosis would be graded according to its severity.

It should be noted that differences in the methods of exercise testing and coronary arteriography were negligible between the groups, and the divergence of results was thus due to patient selection.

Our results imply that some patients with noncritical coronary disease may have a lower total supply of blood to the myocardium than some patients with critical coronary disease. Thus an electrocardiographic criterion that correlates with ischaemia should not be expected to correlate exactly with the existence of critical coronary disease.

Myocardial ischaemia is associated with ST segment changes. ${ }^{19} 20$ In the absence of an adequate supply of blood by collaterals a coronary artery narrowing will result in a reduction of the maximal blood flow. At rest the supply of blood can still be sufficient to prevent ischaemia. At some levels of exercise, however, the demand will exceed the capacity for supplying blood, and ischaemic ST segment changes will occur. This approach explains the results in the angina group but not those in the infarction group.

Table 7 Sensitivity, specificity, and predictive value $P V(+)(\%)$ of three ST criteria based on ST amplitude change for three subgroups of patients in the angina group including those patients with an abnormal $Q$ wave in $C H 2$ for detecting patients with a global flow index $\leqslant 0.4$

\begin{tabular}{|c|c|c|c|c|c|c|c|c|c|}
\hline & \multicolumn{3}{|c|}{ Definite infarction } & \multicolumn{3}{|c|}{ Uncertain infarction } & \multicolumn{3}{|c|}{ Absence of infarction } \\
\hline & Sensitivity & Specificity & $P V(+)$ & Sensitivity & Specificity & $P V(+)$ & Sensitivity & Specificity & $P V(+)$ \\
\hline \multirow{2}{*}{$\begin{array}{l}\text { ST segment depression: } \\
\geqslant 0.033 \mathrm{mV} \text { (lead I) } \\
\geqslant 0.02 \mathrm{mV}(\text { any CH lead }) \\
\geqslant 0.033 \mathrm{mV}(\text { lead I) or } \\
\geqslant 0.2 \mathrm{mV} \text { (any CH lead) }\end{array}$} & $\begin{array}{l}76 \\
60\end{array}$ & $\begin{array}{r}100 \\
93\end{array}$ & $\begin{array}{r}100 \\
94\end{array}$ & $\begin{array}{l}86 \\
57\end{array}$ & $\begin{array}{r}80 \\
100\end{array}$ & $\begin{array}{r}86 \\
100\end{array}$ & $\begin{array}{l}79 \\
79\end{array}$ & $\begin{array}{l}80 \\
73\end{array}$ & $\begin{array}{l}88 \\
83\end{array}$ \\
\hline & 80 & 80 & 95 & 86 & 80 & 86 & 84 & 73 & 84 \\
\hline
\end{tabular}


There are factors indicating that the degree of ischaemia developed by the infarction patients classified as having critical coronary disease was less than would be expected from the angiographic findings. The difference in mean maximal workload between the infarction group and the angina group was larger than would be expected from the difference in age. Few of the patients in the infarction group had severe angina pectoris. In the infarction group neither the existence of critical coronary disease nor the value of the global flow index showed the same degree of correlation with ST segment changes as was found in the angina group. An old infarction indicates that part of the myocardium has changed to scar tissue, for which the demand of blood is negligible. A healed completely infarcted area is electrically inactive, and no ischaemic ST segment changes will originate from such an area. The development of collaterals, supporting the surviving tissue, can to some extent prevent ischaemia even during exercise despite significant narrowing. Consequently, less chest pain and ST segment depression should be expected in these cases. Thus in the infarction group there was no correlation between angina during exercise and the severity of the coronary artery narrowing.

The angina group, however, consisted of $60 \%$ of patients with a myocardial infarction, and yet this group showed a correlation between the ST segment measurements and angiographic classification. This may be explained by a difference between the two patient groups. The patients in the angina group had a progression of their angina and probably also of their ischaemia and coronary disease, but most of the infarction patients had not experienced increasing symptoms since their infarction three years earlier. Thus the heart appears to be able to adapt to a certain degree of coronary artery disease-for example, by developing collaterals-and can function reasonably well.

These findings show that information on coronary artery narrowing alone is not sufficient when findings from coronary arteriography are correlated with the results of exercise electrocardiographic testing. The functional capacity of collaterals and the amount of infarcted ventricular muscle are important factors which must be taken into consideration. The rate of the progression of the coronary artery disease may to a considerable degree determine the ischaemic effect of the narrowing. Furthermore, coronary arteriography is performed with the patient at rest, and data should not be expected to agree exactly with results obtained during stress testing.

The promising results obtained in the angina group agree well with the results from a previous study by Ejdebäck et al in a similarly selected group. ${ }^{10}$ This is encouraging since patients with critical coronary dis- ease may have an increased risk of cardiac events, and prompt detection and treatment may be essential.

\section{CONCLUSION}

In limb lead I the sensitivity for detecting patients with severe coronary artery disease in the angina and infarction groups was $92 \%$ and $29 \%$ respectively, when the patients were classified by a conventional angiographic method. The corresponding values were $88 \%$ and $47 \%$ when a new method for angiographic classification was used. The specificity increased in both patient groups. The difference in results obtained with the two methods for angiographic classification suggests that a more detailed analysis of the site and extent of coronary artery narrowing is valuable, and that the presence of collaterals should be included in the classification.

The divergence of the results between the two groups of patients in their ability to distinguish between severe and less severe coronary artery disease by means of ST segment analysis is evident. The rate of progression of the coronary disease, which was different in the two groups, is proposed as the main reason for this. Thus in the evaluation as to what extent a coronary artery narrowing gives rise to ischaemia the rate of progression is an important factor as it affects the degree of adaptation to the narrowing - for example, by developing collaterals.

\section{References}

1 Simoons ML, Hugenholtz PG, Ascoop CA, et al. Quantitation of exercise electrocardiography. Circulation 1981; 63: 471-5.

2 Goldschlager N, Selzer A, Cohn K. Treadmill stress tests as indicators of presence and severity of coronary artery disease. Ann Intern Med 1976; 85: 277-86.

3 Froehlicher VF Jr, Yanowitz FG, Thompson AJ, Lancaster MC. The correlation or coronary angiography and the electrocardiographic response to maximal treadmill testing in 76 asymptomatic men. Circulation 1973; 48: 597-604.

4 Ellestad MH, Cooke BM Jr, Greenberg PS. Stress testing: clinical application and predictive capacity. Prog Cardiovasc Dis 1979; 21: 431-60.

5 Epstein SE. Value and limitations of the electrocardiographic response to exercise in the assessement of patients with coronary artery disease. Am $\mathcal{f}$ Cardiol 1978; 42: 667-74.

6 Levites R, Anderson GJ. Detection of critical coronary lesions with treadmill exercise testing: fact or fiction? $\mathrm{Am}$ f Cardiol 1978; 42: 533-8.

7 Timmis GC, Westveer DC, Gordon S, Ramos RG, Gangadharan V. Limitations of exercise testing in critical left coronary artery disease. $\mathcal{F}$ Electrocardiol 1979; 12: 241-8.

8 Mason RE, Likar I. A new system of multiple-lead exercise electrocardiography. Am Hean f 1966; 71: 196-205. 
9 Falk KJ, Angelhed JE, Bjurö TI. A program for the processing of multiple-lead exercise ECGs in real time. Comput Programs Biomed 1982; 14: 133-144.

10 Wolthuis RA, Hopkirk A, Keiser N, Fischer JR Jr. T-waves in the exercise ECG: their location and occurrence. IEEE Trans Biomed Eng 1979; 26: 639-43.

11 Ejdebäck J, Angelhed JE, Bjurö T, Falk KJ, Schlossman D, Varnauskas E. Computerized exercise ECG in the diagnosis of critical coronary lesions. Cardiology 1982; 69: 22-33.

12 Judkins MP. Selective coronary arteriography. Part I. A percutaneous transfemoral technic. Radiology 1967; 89: 815-24.

13 Austen WG, Edwards JE, Frye RL, et al. AHA Committee Report. A reporting system on patients evaluated for coronary artery disease. Circulation 1975; 51 (suppl): $5-40$.

14 Friesinger GC, Page EE, Ross RR. Prognostic significance of coronary arteriography. Trans Assoc Am
Physicians 1970; 83: 78-92.

15 Kalbfleisch H, Hort W. Quantitative study on the size of $c$ coronary artery supplying areas postmortem. Am Hean $\mathcal{f}$ 1977; 94: 183-8.

16 Castellanet MJ, Greenberg PS, Ellestad MH. Comparison of S-T segment changes on exercise testing with angiographic findings in patients with prior myocardial infarction. Am $\mathcal{F}$ Cardiol 1978; 42: 29-35.

17 Fukui S, Sato H, Ogidani N, et al. Clinical significance of exercise-induced ST changes in patients with prior myocardial infarction. Fpn Circ f 1981; 45: 1131-7.

18 Johansson SR, McCall M, Wilhelmsson C, Vedin JA. Duration of action of beta blockers. Clin Pharmacol Ther 1980; 27: 593-601.

19 Holland RP, Brooks H. TQ-ST segment mapping: critical review and analysis of current concepts. Am $\mathcal{Y}$ Cardiol 1977; 40: 110-129.

20 Waters DD, Forrester JS. Myocardial ischemia: detection and quantitation. Ann Intern Med 1978; 88: 239-50. 